\title{
Progressing Quality Care Process Metrics for Public Health Nursing: Viewed Through the Lens of a Modified Delphi Approach
}

O’Connor $\mathrm{L}^{1 *}$, McAuliffe $\mathrm{E}^{1}$, Casey $\mathbf{M}^{1}$, Rogers $\mathrm{L}^{1}$, Gallen $\mathrm{A}^{2}$, Glasgow $\mathrm{ME}^{3}$, Nadin $\mathbf{M}^{4}$, White $\mathrm{C}^{5}$, Buckley $\mathrm{C}^{6}$, Giltenane $\mathbf{M}^{4}$, Kavanagh $\mathrm{C}^{4}$, Lane $\mathrm{A}^{4}$ and Barnard $\mathbf{M}^{1}$

${ }^{1}$ UCD School of Nursing Midwifery \& Health Systems, University College Dublin, Ireland

${ }^{2}$ Director of Nursing \& Midwifery Planning Development Unit, National Lead for Nursing and

Midwifery Quality Care Metrics Project, Health Service Executive, Ireland

${ }^{3}$ Professor and Dean, School of Nursing, Duquesne University, Pittsburgh, USA

${ }^{4}$ Quality Care Metrics Health Service Executive, Ireland

${ }^{5}$ Dublin City University, Ireland

${ }^{6}$ Area Director of Nursing \& Midwifery Planning Development Unit, HSE South, Cork, Ireland

*Corresponding author: Laserina O' Connor, Professor of Clinical Nursing, UCD School of Nursing Midwifery \& Health Systems, University College Dublin, Ireland, Tel: 017166460; Email: laserina.oconnor@ucd.ie

\section{Abstract}

Background: Nursing plays a central role in facilitating care in the community setting, yet there is no consensus of public health nurses contribution to care and how to measure what hidden or explicit things they do to provide high quality and safe care. A modified Delphi approach with an expert panel was established with the purpose of identifying quality care process metrics for public health nursing care and respective indicators that could measure their unique and multidimensional contribution to care. This modified Delphi study integrated a four round survey of 218 nurses, face-to-face meetings with a patient representative and key stakeholder holders within public health nursing services with a final consensus meeting inclusive of a panel of 29 expert nurses in the community setting.

Results: Delphi rounds 1-4 led to a consensus on fourteen quality care process nursing metrics and sixty-nine associated indicators incorporating expert panellists' suggestions for the community care setting. Notwithstanding the rating of 'critical' in the Delphi rounds, in depth discussions were conducted on all proposed metrics and indicators at the final consensus meeting and in particular emphasizing the key role performed by public health nurses in the context of 'Maternal Health', 'Care Plan Development and Evaluation' and 'Health Promotion'.

Conclusion: This paper describes through the lens of public health nursing the development of a set of 14 quality care metrics using a modified Delphi technique aligned with a set of 69 corresponding indicators. The challenge now is the implementation of these quality care process metrics so that public health nurses' unique and multidimensional contribution to patientcentered care is measurable in the community setting.

Keywords: Modified Delphi technique; Public health nurses; quality care metric development; Health promotion; Maternal health; Community care 
Abbreviations: PHNs: Public Health Nurses; CHO: Community Healthcare Organizations; NMPDU: Nursing Midwifery Planning Development Unit.

\section{Introduction}

A national project entitled Nursing and Midwifery Quality Care-Metrics expedited the development and national agreement of quality care process metrics and respective indicators that can be used consistently to measure nursing and midwifery care processes in public health nursing services across the Republic of Ireland. The project involved the establishment of a Work-Stream Working Group panel and a panel of specialist experts from Public Health Nursing and community care. These panels represented key stakeholders from the community, academia, and included a patient representative.

\section{Background}

Measurement of high quality care is central to improvement efforts designed to promote accountability in healthcare and professional nursing practice. Quality care metrics and indicators arise from the consistent challenge for measures of high quality care across the spectrum of healthcare ranging from primary, secondary and tertiary care. Nurses comprise the largest cohort of the healthcare professional workforce and are recognized as central to the delivery of safe and skilled care. Understanding, measuring, detecting and reporting the quality of their activities is, therefore always critical, but in particular in the community setting amidst a pandemic.

Public health nurses (PHNs) due to their public health alignment and guiding philosophy are acutely sensitive to any anticipated changes in health policy underpinned by primary care [1]. This is due to the fact that PHNs work in the community and deliver universal low threshold services informed by health promotion and disease prevention [2] and their contribution to high quality care is difficult to quantify. Evidence suggests that a preventive tactic to community based health interventions decreases the utilization of hospital services, progresses the management of chronic illnesses, and empowers patients to self-care [3]. Moreover, patients' illness trajectories are more complex than ever before, and PHNs play a strategic role in shaping and managing these trajectories by co-coordinating care between inter professionals at primary, secondary and tertiary level who at times work in silos. Therefore, the development of a suite of quality care process metrics and indicators for public health nursing services in Ireland will provide an opportunity to measure the safety and quality of such services in the context of complex care trajectories.

\section{The Study}

The study consisted of a 2 round modified Delphi approach on proposed metrics; a 2 round Delphi approach on indicators for the proposed quality care process metrics, four work-stream working group meetings interspersed with the Delphi rounds and a final consensus meeting with additional key stakeholders who had specific expertise aligned with individual quality care process metrics such as 'pain', 'medication safety', 'maternal health' and 'health care associated infection prevention and control'.

\section{Aim and Objectives}

The aim of the study was to develop an evidence based metric system to measure the quality of nursing care within the community setting. The objectives of the Delphi process were to:

- To identify supplementary pertinent quality care process (a) metrics and (b) indicators that was not identified from the systematic review.

- To attain consensus on selected (a) metrics and (b) their respective indicators.

\section{Design}

A modified Delphi approach was selected for three reasons. First, it is participatory, engaging both nurses and midwives in the community, researchers and, a patient representative that capture the visions and care values for the community for which the quality care process metrics and indicators were developed, initiating a collaborative activity and process involving key stakeholders. Secondly, we sought consensus among participants to provide a portrait of nurses and midwives contribution to high quality care in the community setting. Consensus was built through the four rounds of the Delphi, wherein the initial group of collective responses of participants was used as an input in the second and fourth round of the Delphi, generating results that were co-produced with the key stakeholders. Thirdly, the Delphi was viewed as an efficient means to involve a wide range of experts on the front-line of community practice with their 'face-to-face collaborations' being facilitated by the researchers conducting the study. Some argue that physical meetings may deprive the Delphi process of benefits related to anonymity and controlled feedback, however, due to the complexity of the subject area, the face-to face element of the methodology was considered necessary for clarification in areas of disagreement [4].

The main methodological process followed includes the development of an original suite of quality care process metrics and indicators from a systematic review (HSE, 2018) as well as the preparation and implementation of the four- 
round Delphi study to refine and integrate a suite of 43 quality care process metrics and 70 associated indicators in the context of public health nursing services. This modified Delphi approach is described in detail in the following sections.

\section{Stakeholder Panel and Recruitment}

Registered public health nurses within the nine Community Healthcare Organizations (CHO) were eligible to complete the survey if they had experience in community nursing care. CHO's are community healthcare services outside of acute hospitals, such as primary care, social care, mental health, and other health and well-being services across Ireland. Expressions of interest were collected through the efforts of the Nursing Midwifery Planning Development Unit (NMPDU) Directors, Project Officers, and Work-stream Working Group members from January 2017 to June 2017. Participation in the project was by an "opt-in" informed consent approach. Eligible participants received an information package, which was approved by the Research Ethics Committee [HREC LS-XXX] and provided participants with an overview of the study details. For each Delphi round, eligible participants received a formal email invitation and electronic questionnaire through the online survey platform, Survey Monkey. Prior to retrieving any of the Delphi questions, participants received, in the opening page of the online Delphi, the 'Study Information and Consent Agreement' form which enclosed the essential information on which potential participants could base their decision as to whether or not they wished to participate in the Delphi Round. The acceptance of this information and agreed understanding of their participation was then indicated by clicking to proceed onto the subsequent page and commencement of the Delphi Round.

\section{Data Collection}

Data collection of the Delphi Rounds was undertaken from June 2017-October 2017. Delphi round questions were developed, administered, and completed through the commercial online survey platform, Survey Monkey. By using this electronic survey, the possibility of geographic dispersion among participants was heightened which facilitated the collection of varying perspectives on the quality care process metrics and indicators.

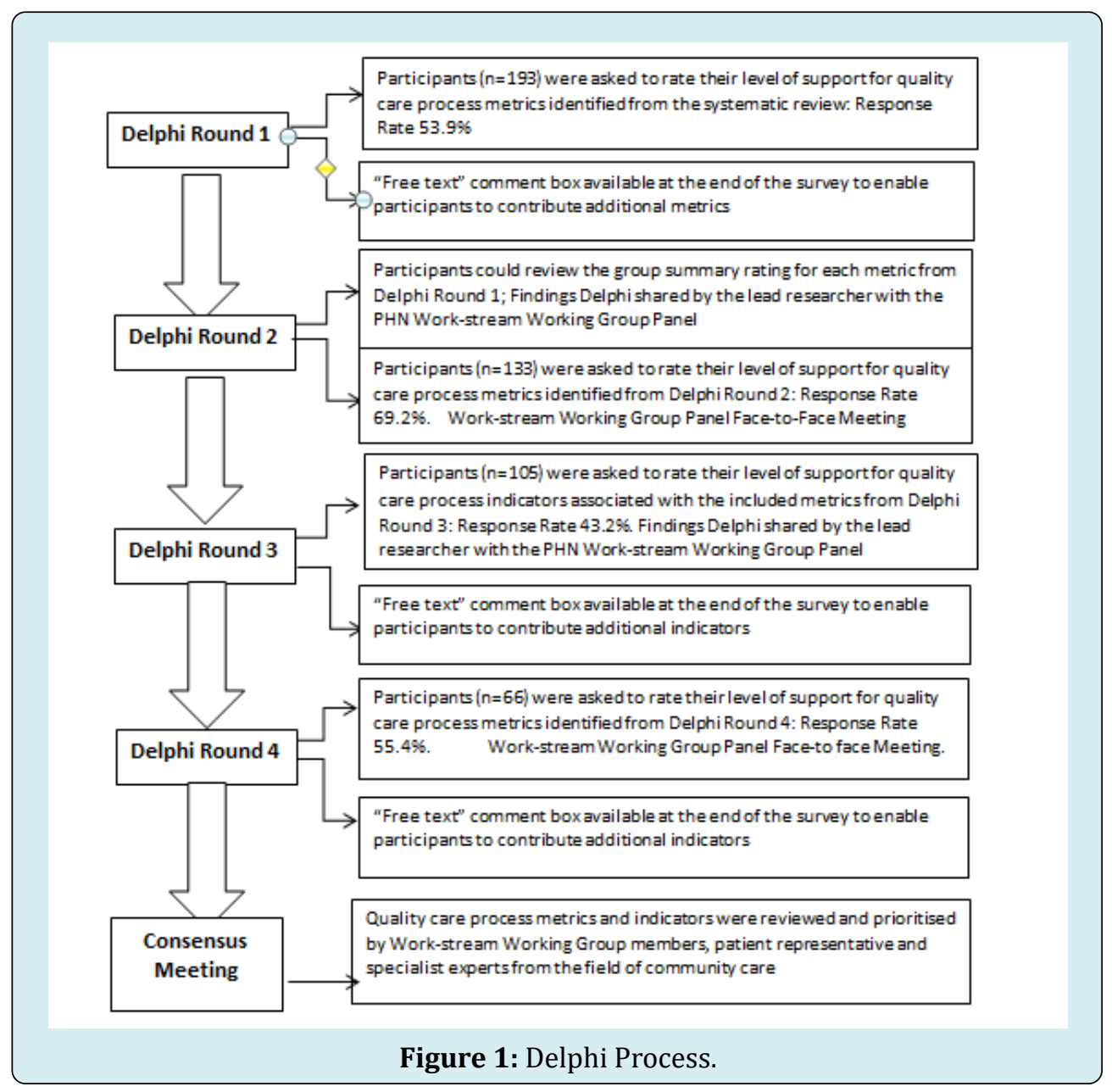

O'Connor L, et al. Progressing Quality Care Process Metrics for Public Health Nursing: Viewed Through the Lens of a Modified Delphi Approach. Nurs Health Care Int J 2020, 4(4): 000229. 
The modified Delphi approach incorporated four rounds and participants were given 3 weeks to respond anonymously to each round. The first two Delphi rounds (Delphi Round 1 and 2) focused on agreeing a suite of quality care process metrics and incorporated a conference call after Delphi Round 1 and a face-to-face meeting with the Work-stream Working Group panel following Delphi round 2. Similarly, the second two Delphi rounds (Delphi Round 3 and 4) focused on agreeing the associated quality care process indicators for the selected metrics and incorporated a conference call after Delphi 3 and a face-to-face meeting with Work-stream Working Group panel following Delphi 4 followed by a final meeting with the key stakeholders and experts in their specialist fields $(n=29)$ in the context of a specific metric to enhance consensus (Figure 1).

\section{Data Analysis}

The quantitative analysis of participant responses was performed using the online survey platform, Survey Monkey. Likert scale responses for each metric and indicator were categorized into 3 tertiles. The categories were 1-3 "not important", 4-6 "important but not critical", and 7-9 "critical". Consensus for inclusion of a metric was agreed and predetermined by the research team. 70 percent of the votes were required to fall within the "critical" range of 7-9 for the measure to be included in the subsequent Delphi rounds. Delphi Round 1 and Delphi Round 3 concluded with free text comments for participants to contribute additional metrics or indicators that they felt were critical to practice, and were given an opportunity to defend or expand their Likert ratings with qualitative notes. Content analysis was used to explore the participants' annotations and make sense of the most meaningful bits of the data. This approach provided a means to move deeper into drawing meaning from that data which was necessary to develop new process measures and to evaluate the acceptability of the prioritised metrics and indicators $[5,6]$.

Feedback is considered a vital constituent of the Delphi process [4]. Thus, each participant received a copy of their individual response following Delphi Round 1 and Delphi Round 3 to help inform their decision for the subsequent rounds. The statistical results of each Delphi Round were also reported prior to the commencement of the proceeding surveys. By repeatedly supplying this controlled feedback, respondents were informed of their position in relation to the group's collective opinion, which assisted in decisions about replies in future rounds $[7,8]$.

\section{Validity and Reliability}

By using a broad sampling criterion, a representative sample was recruited; facilitating an illustration of a heterogeneous sample, heightening the credibility of the results. When consensus is achieved, it can also be reasoned that concurrent validity is assured, as experts with in-depth knowledge of the subject area identified and agreed upon the necessary metrics and indicators to measure the quality of nursing care $[9,10]$.

\section{Delphi Findings}

The response rates between Delphi surveys varied between 43.2\%-69.2\%. As illustrated in Table 1 although some participants consented to take part in the Delphi process their responses were not included in the overall response rate as they only provided their name and email address without contributing to the consensus process (Table 1$)$. The majority of survey participants $(56.42 \%)$ indicated a nursing grade of PHN or equivalent, aged 38- 50 with some respondents (18.81\%) in assistant director of nursing positions with a geographic representation from all 9 CHOs.

\begin{tabular}{|c|c|c|c|}
\hline Delphi Round & Unique Responses & Completed Responses & Response Rate \\
\hline $\mathbf{1}$ & 218 & 193 & $53.90 \%$ \\
\hline $\mathbf{2}$ & 159 & 133 & $69.20 \%$ \\
\hline $\mathbf{3}$ & 126 & 105 & $43.20 \%$ \\
\hline $\mathbf{4}$ & 78 & 66 & $55.40 \%$ \\
\hline
\end{tabular}

Table 1: Summary of Responses.

\section{Delphi Round 1 and Delphi 2}

The first-round Delphi questionnaire presented the initial suite of 43 quality care process metrics, organized in eight care process domains; 'Wounds and Ulcers', 'Falls', 'Patient Safety', 'Health Care Associated Infection', 'Chronic Condition Management', 'Care Co-ordination', 'Interpersonal', and 'Continence' and included an introduction to the project with a quality care process metric exemplar to help participants clearly understand the content of the metrics presented.

The second-round Delphi questionnaire presented 56 quality care metrics that included 13 new metrics suggested by Delphi 1 participants who were again invited to not only 
rate each metric but also to defend or expand their Likert ratings with qualitative notes. Following the quantitative analysis of participant responses, eleven quality care process metrics were excluded. The remaining 45 proposed metrics were ranked in descending order of importance and presented at a face-to-face meeting with experts and a patient representative from the PHN Work-stream Working Group Panel in August 2017 and this process enabled further modifications to the suite of quality care process metrics that materialised from Delphi rounds 1 and 2 (Figure 2). The 45 metrics were subsequently condensed into 15 quality care process metrics based on refinements agreed at the Workstream Working Group meeting which were then presented with their associated indicators in Delphi Rounds $3(\mathrm{n}=70)$ and $4(\mathrm{n}=69)$ (Figure 3).

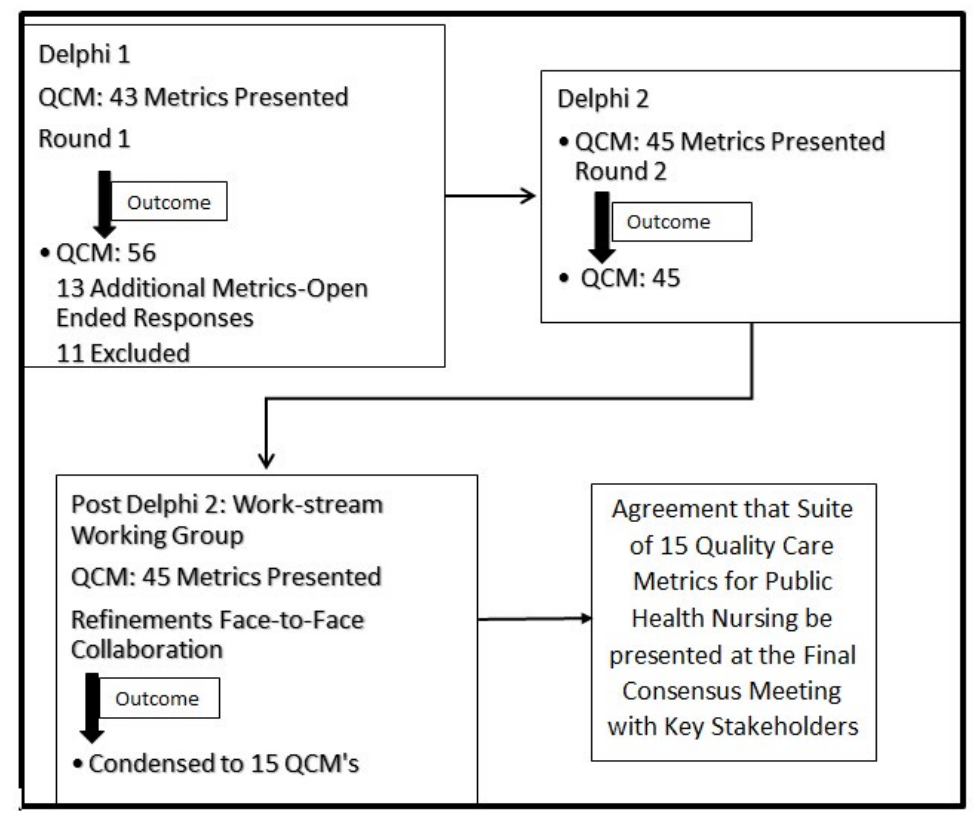

Figure 2: Number of Quality Care Process Metrics-Delphi Rounds 1 \& 2.

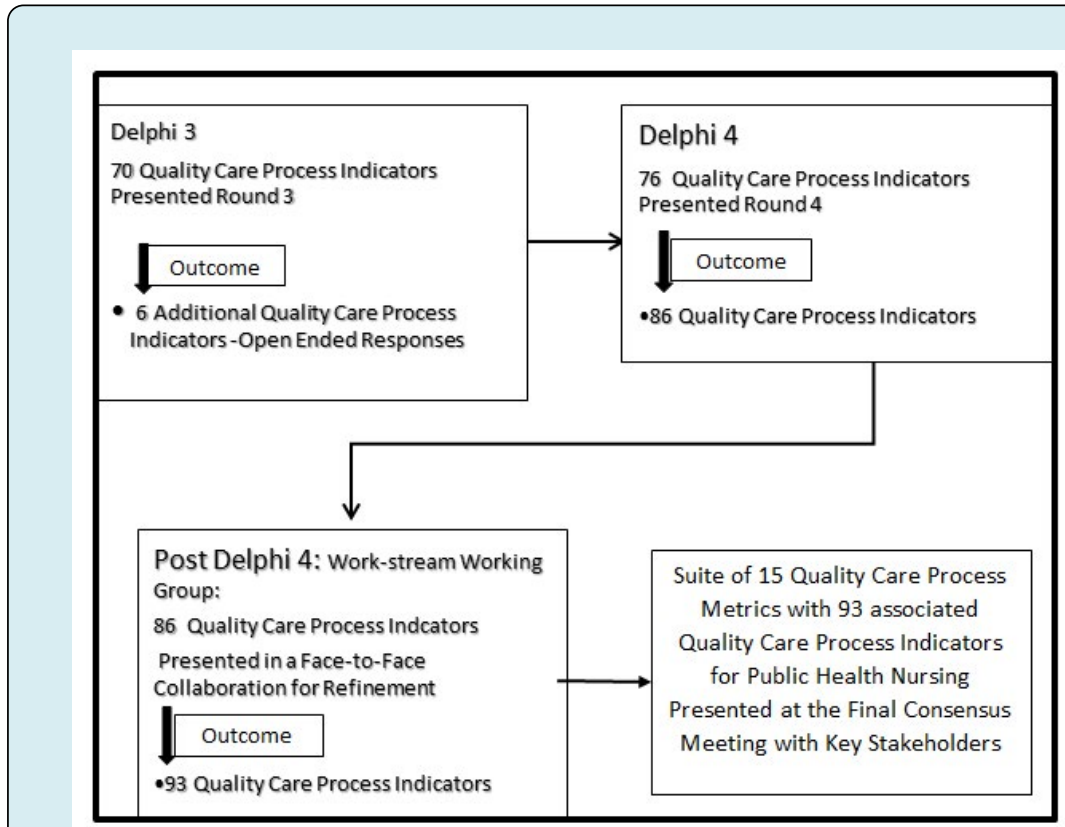

Figure 3: Number of Quality Care Process Indicators -Delphi Rounds $3 \& 4$. 


\section{Face-to-Face Group Panel Discussion Post Delphi Rounds}

The findings of the Delphi Rounds (1-4) were presented at the Work-stream working group panel meetings and the results from the qualitative notes from the participants revealed the breadth of work undertaken by public health nurses in the community. The portrait of the role created by the participants reflected the complexity of the role such as leader, educator, advocate, and case manager of complex cases and provider of skilled care in acute episodes that transition from the tertiary setting inclusive of care coordination of services to enable the person with advanced disease to take the next step to live at home that includes their future capabilities.

Concerns were noted from some panellists around the terminology of the quality care process metric 'Maternal Surveillance' that suggested a punitive perspective rather than a true representation of the role undertaken by the PHN such as supporting and building a women's pattern of confidence and fostering autonomy during a time of significant transition and role development. One panellist posed the following question which certainly focused the response from the group to acknowledge the value of changing the metric title to 'Maternal Health', and resulting in agreement from the entire group to explore this refinement at the final consensus meeting following Delphi Round 4.

'If we have a metric titled 'Maternal Surveillance' ... would it improve the quality of the care for mothers who are seeking to provide the best possible approach to take care of their baby and themselves and including their partner... my experience would tell me .... big no...so 'Maternal Health' embodies mum, baby, partner and public health nurse'.

Further, there was much discussion about the quality care metric 'Care Plan Development and Evaluation' which seemed to highlight the hidden pre-emptive role of the public health nurse in reducing hospital admissions by providing care in the appropriate setting, and promoting holistic care with a domino effect on improving health related quality of life for the patient and their family. One expert public health nurse summed up her interpretation of this metric;

'Care Plan Development and Evaluation' should be about a patient-centred care plan that expedites the delivery of care...safeguards that nothing is forgotten...and records and measures the quality of care given to the patient by the public health nurse', while another expert emphasized the following; 'the care plan must be clear, accurate, contemporaneous and evidence-based because health care is complex and different clusters of patients require different interventions and different personalized care goals and one size does not fit all in the community even if they have been considered to have same needs'. The use of standardized assessment tools in this metric and comprehensive inter professional communication strategies during care transitions from the tertiary setting to the community setting and vice versa were consistently ranked by all the Work-stream working group panellists to have high relevance, engagement and adherence impact to optimize public health nurses' roles and scope of practice across the care trajectory spectrum.

The dimensions of their practices in the community were discussed in-depth based on the quality care process metrics $(n=15)$ and the indicators (n-69). One quality care process metric 'Health Promotion' ranked as 'critical at $>89 \%$ in Rounds 1 and 2 provoked much debate by all panellists as the importance of hearing the voices of the community was perceived as critical as one panellist articulated in the following excerpt:

'Health promotion is at the core of all interventions and interactions with patients, their families and the community' and expanded on by another expert public health nurse who emphasized that 'our interprofessional collaboration with the community stakeholders, and local knowledge of the community means we can gain access that allows us to have an in-depth insight into the individual's preferences, beliefs and needs'. The evolving patient-centered role of the public health nurse was perceived to be embedded in community health promotion and prevention, incorporating health education as part of care-co-ordination for patients and families and the population at large.

\section{Public Health Nursing Final Consensus Findings}

A face-to-face consensus meeting between the research team, PHN Work-stream key stakeholders, patient representative and additional specialist experts from the field of community nursing $(\mathrm{N}-29)$ were present to add further clarity and validity pertinent to the respective suite of quality care process metrics and indicators. Group consensus was measured for each metric and indicator through the process of anonymous electronic voting (Poll Everywhere) to expedite the presentation of voting results (Figure 4). A judgment framework was developed, using a modified version of the eRegistries indicator evaluation tool by Flenady, et al. to assist in the selection of Nursing and Midwifery Quality Care-Metrics [11].

One quality care process metric was removed, namely 'Professional and Ethical Approach to Care', ranked as important but not feasible to measure currently, and 29 indicators deemed repetitive were removed following the Consensus Meeting. The quality care metric titles of 'Client/Family/Carer Experience', 'Maternal Health', 'Child 
Development Assessment', 'Child and Family Health Needs Assessment,' 'Child Welfare and Protection' and 'Safeguarding Vulnerable Adult' were refined following expert guidance from the PHN Work-stream Working Group panel and agreed by the entire consensus group. Subsequently, 14 nursing quality care process metrics and 67 associated indicators were developed for the public health nursing services (Table 2).

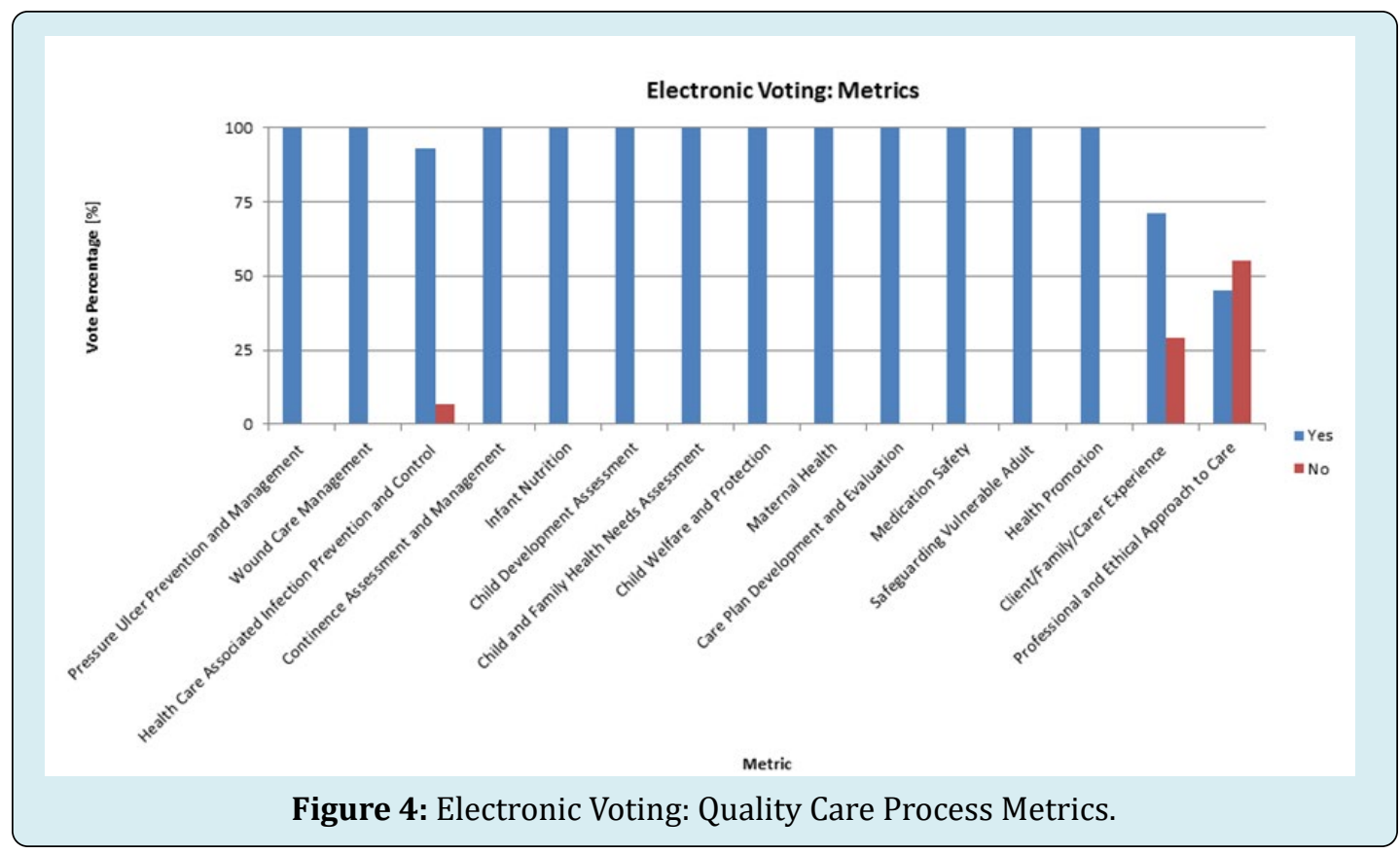

\begin{tabular}{|c|c|}
\hline $\begin{array}{l}\text { Quality Care } \\
\text { Process Metrics }\end{array}$ & Quality Care Process Indicators \\
\hline \multirow{6}{*}{$\begin{array}{l}\text { Pressure Ulcer } \\
\text { Prevention and } \\
\text { Management }\end{array}$} & A pressure ulcer risk assessment was recorded using a validated tool \\
\hline & $\begin{array}{l}\text { There is evidence that the client's pressure ulcer risk was reassessed and documented using a validated } \\
\text { tool }\end{array}$ \\
\hline & $\begin{array}{l}\text { If a pressure ulcer is present, the grade/stage/category has been recorded on the relevant } \\
\text { documentation }\end{array}$ \\
\hline & $\begin{array}{l}\text { There is evidence that evaluation of the pressure ulcer has been recorded and the client's response to } \\
\text { interventions are documented }\end{array}$ \\
\hline & $\begin{array}{c}\text { Documented the use of pressure distributing devices and alternative pressure therapies based on skin } \\
\text { assessment }\end{array}$ \\
\hline & $\begin{array}{l}\text { Documented the verbal and written guidance provided to the client/family/carer to reduce the risk of } \\
\text { developing or worsening pressure ulcers, ensuring that they understand the information given. }\end{array}$ \\
\hline \multirow{4}{*}{$\begin{array}{l}\text { Wound Care } \\
\text { Management }\end{array}$} & Completed an assessment of the wound using a validated tool \\
\hline & $\begin{array}{l}\text { Identified and documented the risk factors impacting effective wound healing as per the National } \\
\text { Wound Management Guidelines }\end{array}$ \\
\hline & There is documented evidence that a wound care plan has been developed \\
\hline & $\begin{array}{c}\text { There is documented evidence that a wound care plan has been evaluated and updated if clinically } \\
\text { indicated. }\end{array}$ \\
\hline \multirow{2}{*}{$\begin{array}{l}\text { Health Care } \\
\text { Associated } \\
\text { Infection } \\
\text { Prevention and } \\
\text { Control }\end{array}$} & There is documented evidence that the client's infection risk has been assessed and recorded \\
\hline & $\begin{array}{c}\text { There is documented evidence of the education given if the client has been identified as at risk of } \\
\text { infection. }\end{array}$ \\
\hline
\end{tabular}




\begin{tabular}{|c|c|}
\hline \multirow{9}{*}{$\begin{array}{c}\text { Continence } \\
\text { Assessment and } \\
\text { Management }\end{array}$} & A continence assessment has been completed \\
\hline & $\begin{array}{l}\text { There is documented evidence that a continence reassessment has been completed within } 1 \text { year at a } \\
\text { minimum }\end{array}$ \\
\hline & $\begin{array}{l}\text { Documented the education given to the client regarding therapeutic options to improve continence } \\
\text { control }\end{array}$ \\
\hline & $\begin{array}{l}\text { There is documented evidence of the appropriate containment products prescribed and the education } \\
\text { given to the client on the correct use and management of containment products }\end{array}$ \\
\hline & $\begin{array}{l}\text { If a client has a urinary catheter the rationale for insertion, type of catheter, size of catheter, the date of } \\
\text { insertion and the date of removal have been documented as per National Guidelines }\end{array}$ \\
\hline & $\begin{array}{l}\text { The education given to the client/family/carer on catheter management has been documented as per } \\
\text { National Guidelines }\end{array}$ \\
\hline & $\begin{array}{l}\text { There is documented evidence that the client's bowel pattern has been assessed and documented using } \\
\text { a validated tool }\end{array}$ \\
\hline & A bowel management plan has been developed with the client/family/carer \\
\hline & There is documented evidence that the bowel management plan has been evaluated. \\
\hline \multirow{2}{*}{$\begin{array}{l}\text { Client/Family/ } \\
\text { Carer Experience }\end{array}$} & $\begin{array}{l}\text { There is a record that verbal/written informed consent was obtained prior to delivering healthcare and } \\
\text { interventions to the client }\end{array}$ \\
\hline & $\begin{array}{l}\text { There is documented evidence that verbal/written informed consent has been obtained prior to } \\
\text { referring the client to other service providers. }\end{array}$ \\
\hline $\begin{array}{c}\text { Health } \\
\text { Promotion }\end{array}$ & $\begin{array}{c}\text { There is evidence that the client/ family/ carer has received the appropriate health promotion pertinent } \\
\text { to their individual circumstance }\end{array}$ \\
\hline \multirow{14}{*}{$\begin{array}{c}\text { Care Plan } \\
\text { Development } \\
\text { and Evaluation }\end{array}$} & An assessment has been completed to identify the holistic needs of the client \\
\hline & $\begin{array}{l}\text { The care plan is evident and reflects the individuals current condition, the goals and plan for care which } \\
\text { has been developed with the client/ family/ carer }\end{array}$ \\
\hline & Evaluation of the care plan is evident and has been adjusted in accordance to the client's changing needs \\
\hline & $\begin{array}{l}\text { There is documented evidence in the care plan that discharge planning has been initiated in } \\
\text { collaboration with the client/ family/ carer and other service providers where indicated }\end{array}$ \\
\hline & $\begin{array}{l}\text { On discharge, all education given to the client/ family/carer has been documented including the contact } \\
\text { details for the public health nursing service if further support is required in the future }\end{array}$ \\
\hline & All entries into client records are documented in accordance with NMBI Guidelines \\
\hline & $\begin{array}{l}\text { There is documented evidence that the client's risk of malnutrition has been screened using a validated } \\
\text { tool }\end{array}$ \\
\hline & $\begin{array}{l}\text { There is documented evidence that a plan of care has been developed based on the client's risk of } \\
\text { malnutrition. }\end{array}$ \\
\hline & $\begin{array}{l}\text { There is documented evidence that the client's risk of malnutrition has been screened again as } \\
\text { appropriate }\end{array}$ \\
\hline & A falls risk assessment has been recorded where indicated \\
\hline & $\begin{array}{l}\text { There is documented evidence that the client/family/carer are made aware of the client's falls risk and } \\
\text { provided with information relating to interventions to prevent falls }\end{array}$ \\
\hline & $\begin{array}{l}\text { Completed a comprehensive pain assessment using a validated tool that is consistent with the client's } \\
\text { age, condition and ability to understand when indicated }\end{array}$ \\
\hline & $\begin{array}{l}\text { There is documented evidence that the client's pain is reassessed using a validated tool during the pain } \\
\text { treatment period if indicated }\end{array}$ \\
\hline & $\begin{array}{l}\text { Interventions are recorded and communicated with the relevant healthcare provider when there is a } \\
\text { need for the initiation of pain management, report of severe pain or modification of pain treatment plan. }\end{array}$ \\
\hline
\end{tabular}




\begin{tabular}{|c|c|}
\hline \multirow{7}{*}{$\begin{array}{l}\text { Medication } \\
\text { Safety }\end{array}$} & $\begin{array}{l}\text { Completed and documented the client's relevant medication history, current medication treatment plan } \\
\text { and adherence to treatment plan }\end{array}$ \\
\hline & $\begin{array}{l}\text { All prescribed medications are administered in accordance with NMBI Medication Management } \\
\text { Guidelines }\end{array}$ \\
\hline & $\begin{array}{l}\text { Prescribed medications not administered have been documented in the care plan and appropriate action } \\
\text { taken }\end{array}$ \\
\hline & Monitored and documented the patient's response to the medication administered \\
\hline & $\begin{array}{l}\text { Monitored, managed and documented in accordance with medication management policies, procedures, } \\
\text { protocols and guidelines (PPPG) if an adverse drug event has occurred }\end{array}$ \\
\hline & $\begin{array}{l}\text { The administration, management and disposal of Controlled Drugs and recording of same is in } \\
\text { accordance with NMBI Guidelines and Local PPPGs. }\end{array}$ \\
\hline & There is documented evidence of the client education on prescribed medications administered. \\
\hline \multirow{5}{*}{ Maternal Health } & There is documented evidence that a comprehensive assessment has been completed \\
\hline & There is documented evidence that all interventions have been evaluated as appropriate \\
\hline & $\begin{array}{l}\text { At the first postnatal visit and subsequent follow up visits, a holistic plan of care has been developed if } \\
\text { necessary }\end{array}$ \\
\hline & $\begin{array}{l}\text { If a mother is identified as at risk of developing a mental health problem using a validated tool in the } \\
\text { postnatal period, there is documented evidence of the support provided and the referrals made }\end{array}$ \\
\hline & $\begin{array}{l}\begin{array}{l}\text { The information and education provided to the mother/family about maternal health has been } \\
\text { documented. }\end{array}\end{array}$ \\
\hline \multirow{4}{*}{ Infant Nutrition } & There is documented evidence of the information given to mothers who choose to breastfeed \\
\hline & $\begin{array}{l}\text { There is documented evidence that any challenges relating to breastfeeding have been assessed using a } \\
\text { validated tool }\end{array}$ \\
\hline & There is documented evidence that breastfeeding progress has been evaluated \\
\hline & $\begin{array}{l}\text { There is evidence that tailored education has been given to those who have chosen to formula feed their } \\
\text { infant. }\end{array}$ \\
\hline \multirow{3}{*}{$\begin{array}{c}\text { Child } \\
\text { Development } \\
\text { Assessment }\end{array}$} & $\begin{array}{l}\text { The child's health and developmental progress has been assessed and documented at the core health } \\
\text { visit in accordance with National Guidelines }\end{array}$ \\
\hline & A care plan outlining the needs of the child has been developed with the family if indicated \\
\hline & There is documented evidence that the care plan has been evaluated and updated as required. \\
\hline \multirow{4}{*}{$\begin{array}{l}\text { Child and Family } \\
\text { Health Needs } \\
\text { Assessment }\end{array}$} & $\begin{array}{l}\text { There is documented evidence that a comprehensive assessment of the child and family's health needs } \\
\text { was completed where specific concerns are identified }\end{array}$ \\
\hline & There is documented evidence that the child and family's health needs interventions are recorded \\
\hline & There is documented evidence that the child and family's health needs interventions are evaluated \\
\hline & $\begin{array}{l}\text { There is documented evidence that an appropriate referral has been made in accordance with Local and } \\
\text { National Guidelines. }\end{array}$ \\
\hline \multirow{3}{*}{$\begin{array}{l}\text { Child Welfare } \\
\text { and Protection }\end{array}$} & $\begin{array}{l}\text { If a child welfare/protection issue is identified or it is reported, there is documented evidence of the } \\
\text { issue and the referral made in accordance with Local Policy and National Guidelines }\end{array}$ \\
\hline & $\begin{array}{l}\text { The information provided to the parents about the referral or the rationale for not informing the parents } \\
\text { has been documented }\end{array}$ \\
\hline & $\begin{array}{l}\text { If there is an immediate risk to the child's safety, there is documented evidence that the appropriate } \\
\text { services have been contacted and an urgent referral made in accordance with Local Policy and National } \\
\text { Guidelines. }\end{array}$ \\
\hline
\end{tabular}




\begin{tabular}{|l|c|}
\hline \multirow{2}{*}{$\begin{array}{c}\text { Safeguarding } \\
\text { Vulnerable Adult }\end{array}$} & $\begin{array}{c}\text { If a client has been identified as a vulnerable adult where there are safeguarding concerns, there is } \\
\text { documented evidence that an immediate plan of care has been developed }\end{array}$ \\
\cline { 2 - 3 } & $\begin{array}{c}\text { There is documented evidence that the appropriate interventions are recorded } \\
\text { If a client has been identified as at risk of abuse or has suffered abuse/harm, there is documented } \\
\text { evidence that a referral has been sent to the appropriate services according to National Policy. }\end{array}$ \\
\hline Total Metrics: 14 & Total Indicators: $\mathbf{6 9}$ \\
\hline
\end{tabular}

Table 2: Final Set of Quality Care Process Metrics and Indicators for the Community Care Setting.

\section{Discussion}

The structured panel approach was a convenient and operational way to engage a variety of key stakeholders. The expert panel consisted of a patient representative, researchers, nurse-leaders, and nurses from different community healthcare organizations with an extensive understanding of public health nursing services and or quality care nursing metrics. The varieties of the panel members increased the potential for generalizability and credibility of the Delphi findings is scientifically sound and has broad applicability for public health nursing services. By providing the participants in the Delphi Rounds an opportunity to provide individual ratings, rankings and open-ended comments ensured that more sensitive and critical day-today issues could be raised by participants.

During the face-to-face meetings, an experienced principal investigator who was also an advanced nurse practitioner facilitated the Work-stream working groups' panel face-to-face discussions and sustained fairness among all panel members. This discussion provided opportunities for members to engage in rich dialogue where public health nursing quality care process metrics and associated indicators were discussed prior to the final consensus meeting. Clarity was brought to the initial suite of quality care metrics, and refinements occurred through the final panel consensus.

There are limitations associated with our modified Delphi panel process including the potential for selection bias. To minimize this bias, the research team used a similar process used by members of the research team and sought recommendations from unbiased national project advisors including an international expert reviewer of the entire project trajectory. Our panel had only one patient representative and therefore, minimal patient representation may have impacted on the study results as they can have different perspectives and priorities associated with their care experiences in the community setting. The response rates across each Delphi Round varied from 69.2\% to $43.2 \%$ which is indicative perhaps of the lengthy sustained engagement required of participants with four Delphi Rounds, despite consistent encouragement by nursing and midwifery project officers nationally and highlights the need to pilot test the suite of proposed metrics and indicators in routine community practice to evaluate their feasibility, reliability, and construct validity.

Our findings outline, from the perspective of community care that public health nurses contribution to care can be quantified and realized through the implementation of the robust suite of quality care process metrics $(n=14)$ and their associated indicators $(n=69)$. The utilization of this suite of metrics and indicators will demonstrate not only their unique, multifaceted contribution but will also promote accountability for the care public health nurses provide on a day-to-day basis. Measuring what public health nurses do and the quality of care they deliver is essential in demonstrating their evolving roles with communities and populations that face complex, multidimensional challenges such as public health threats that currently affect at risk populations; i.e., emerging infectious diseases [12]. Consequently, 'Health Promotion' and 'Health Care Associated Infection Prevention and Control' were two of the robust quality care metrics ranked as 'critical' by all Delphi participants with agreement of expert panellists in this study and demonstrates the community participatory health promotion and preventive role of the public health nurse as they move their practice into the future and can now be quantified.

All of the Delphi participants and panellists agreed that 'Maternal Health' was a critical quality care process metric to be measured as public health nurses emphasized their role in supporting and providing reassurance to mothers during the home visit in the early postpartum period. The expert panel highlighted the intangible aspects of the home visit that need to be captured. There is a growing body of literature that reports the importance of paying attention to the "softer" health outcomes including maternal self-confidence and empowerment that have been constructed as less important than health outcomes that are more tangible and physical and mothers' overwhelming discussions of the value of the PHNs visits in the home care environment [13-15].

The panellists discussed the quality care metric 'Care Plan Development and Evaluation' in-depth and all were in agreement with the Delphi findings that meticulous 
attention to standardized discharge planning summaries was also congruent upon an interdisciplinary approach to care that involves PHNs in the first instance to co-ordinate interventions depending on the clinical context and the patient and family or caregivers needs, to replace the siloed approach that exists. This finding is similar to what public health nurses have identified in previous research that explored PHNs perceptions of caring for late preterm infants and challenges in meeting the needs of families in the community [16].

\section{Conclusion}

The need to deliver greater value and increased efficiency while guaranteeing ever-higher quality care is placing a requirement on community healthcare organizations to provide evidence of the quality and safety of their care. This study presents the process employed to develop a robust suite of quality care process metrics and respective indicators that can be used to consistently measure care processes in the public health nursing setting. By creating a national suite of quality care process metrics and indicators, more robust monitoring can be achieved which will enable the provision of evidence for any national level changes to policy and practice that may be required to improve care delivery. The importance of an evidence-based approach in persuading staff to adopt the suite is also evident from the literature [17-20]. It is suggested that staff are more likely to adopt a practice if they know there is scientific evidence to support that practice. The collaborative, participatory approach used ensures the relevancy of the developed quality care process metrics and indicators, engenders participant ownership, increasing the capacity for adoption of the chosen suite in the community care setting and heightens the sustainability of metric and indicator use in practice as the nurses involved in the research process have become advocates for the developed suite [21]. Through using this robust collaborative research design a suite of 14 quality care process metrics and 69 associated indicators were developed for the public health nursing setting.

\section{Recommendations}

The implementation of a suite of 14 quality care process metrics and 69 associated indicators will require robust evaluation in the public health nursing setting. Adherence is a key challenge for any new guideline or measurement and in order to ensure the suite is fully utilized it would be important to explore any issues that might arise during the pilot testing of the quality care metrics and indicators. Consequently, there is a need to evaluate not only summative endpoint outcomes following implementation but also a requirement to perform formative and process evaluations of implementation [22]. Thus, a robust approach is required to examine the impact of the newly developed quality care process metrics and indicators on nursing and midwifery care processes in the setting of public health nursing.

Clearly, research is required to determine the optimal combinations of quality care nursing process metrics and indicators components, and in which context do they work or do not in the community care environment.

Furthermore, including patients in the evaluation process would be very important as they form their own, highly relevant assessments of quality that affect their use of care and adherence to treatment and, ultimately, population health outcomes [23]. Therefore, understanding the patient experience would give direct insight into what is and is not working towards achieving high quality of care in the context of public health nursing services.

Future Delphi consensus expert panels would benefit from caregiver engagement to ensure that their views are adequately represented.

\section{References}

1. WHO (2008) The World Health Report 2008 - primary Health Care (Now More Than Ever), WHO, Geneva, Switzerland.

2. Clancy A, Leahy Warren P, Day M, Mulcahy H (2013) Primary health care: Comparing public health nursing models in Ireland and Nprway. Nursing Research and Practice 2013: 9.

3. Doherty J, Govender R (2004) The cost-effectiveness of primary care services in developing countries: a review of the international literature. Disease Control Priorities Project.

4. Boulkedid R, Abdoul H, Loustau M, Sibony O, Alberti C (2011) Using and Reporting the Delphi Method for Selecting Healthcare Quality Indicators: A Systematic Review. Plos One 6(6): e20476.

5. Coffey A, Atkinson P (1996) Making Sense of Qualitative Data, Complementary research Strategies, Sage, Thousand Oaks, CA, pp: 2-53.

6. Krippendorff K (2004) Content Analysis: An Introduction to Its Methodology. Sage, Thousand Oaks, CA.

7. McKenna HP (1994) The Delphi technique: A worthwhile research approach for nursing? Journal of Advanced Nursing 19(6): 1221-1225.

8. Hasson F, Keeney S, McKenna H (2000) Research guidelines for the Delphi survey technique. J Adv Nurs 
32(4): 1008-1015.

9. Williams P, Webb C (1994) The Delphi technique: A methodological discussion. Journal of Advanced Nursing 19(1): 180-186.

10. Flenady V, Wojcieszek AM, Fjeldheim I, Friberg IK, Nankabirwa V, et al. (2016) eRegistries: indicators for the WHO Essential Interventions for reproductive, maternal, newborn and child health. BMC Pregnancy and Childbirth 16(1): 293.

11. Murphy F, Doody O, Lyons R, Brenner M, O Connor L, et al. (2019) A guidance framework to aid in the selection of Nursing and Midwifery care process metrics and indicators. Nursing Open 6: 948-958.

12. Kulbok P, Thatcher E, Park E, Mezzaros P (2012) Evolving public health nursing roles: Focus on community participatory health promotion and prevention. Online J Issues Nurs 17(2): 1.

13. Aston M, Etowa J, Price S, Vukic A, Hart C, et al. (2016) Public health nurses and mothers challenge and shift the meaning of health outcomes. Glob Qual Nurs Res 3.

14. Glavin K, Leahy Warren P (2013) Postnatal depression is a public health nursing issue: perspectives from Norway and Ireland. Nurs Res Pract 2013.

15. Melby L, Obstfelder A, Helles R (2018) We tie up the loose ends': Homecare nursing in a changing health care landscape. Global Qualitative Nursing Research 5.

16. Currie G, Dosani A, Premji S, Reilly S, Lodha A (2018) Caring for late preterm infants: public health nurses' experiences. BMC Nursing 17: 16.

17. McSherry R (1997) What do registered nurses and midwifes feel and know about research? Journal of Advanced Nursing 25(5): 985-998.

18. Nolan M, Morgan L, Curran M, Clayton J, Gerrish K, et al. (1998) Evidence-based care: can we overcome the barriers? British Journal of Nursing 7(20): 1273-1278.

19. Upton D, Upton P (2005) Nurses' attitudes to evidencebased practice: impact of a national policy. British Journal of Nursing 14(5): 284-288.

20. Majid S, Foo S, Luyt B, Zhang X, Theng YL, et al. (2011) Adopting evidence-based practice in clinical decision making: nurses' perceptions, knowledge, and barriers. Journal of the Medical Library Association 99(3): 229236.

21. Jagosh J, Macaulay AC, Pluye P, Salsberg J, Bush PL, et al. (2012) Uncovering the benefits of participatory research: implications of a realist review for health research and practice. Milbank Q 90(2): 311-346.

22. Stetler CB, Legro MW, Wallace CM, Bowman C, Guihan $M$, et al. (2006) The Role of Formative Evaluation in Implementation Research and the QUERI Experience. J Gen Intern Med 21(S2): S1-S8.

23. (2018) Health Service Executive. Nursing \& Midwifery Quality Care-Metrics (QC-M).

24. O'Connor L (2019) The Nature of Scholarship, A Career Legacy Map and Advanced Practice. Springer, Switzerland. 